DOCTRINA

\title{
La notificación de los actos administrativos de efectos singulares y el derecho a la certidumbre jurídica en Chile
}

\author{
The notification of administrative acts of singular effects and the right \\ to legal certainty in Chile
}

\section{Gladys Camacho Cépeda (iD) \\ Universidad de Chile}

\begin{abstract}
RESUMEN La Ley 19.88 o define al acto administrativo como un instituto dotado de intensos atributos, entre otros, la presunción de legalidad, imperio y exigibilidad frente a sus destinatarios. Estas características reconocidas por el legislador se justifican en la función vicarial de la Administración del Estado al servicio del interés general. No obstante, para que la decisión administrativa expresada en un acto administrativo pueda gozar de esos atributos debe cumplir con unas formalidades esenciales que la ley le impone. En este trabajo se aborda una de esas formalidades: la notificación para el caso de actos de efectos particulares. Se destaca su conexión con el principio del debido proceso, configurándose un deber de la Administración con efectos jurídicos significativos. Por otra parte, el incumplimiento del deber de notificar tiene importantes efectos tanto para el administrado y sus bienes, como para la realización de la finalidad buscada por la decisión administrativa.
\end{abstract}

PALABRAS CLAVE Procedimiento administrativo, notificación del acto administrativo, acto administrativo, debido proceso.

ABSTRACT Law 19,880 defines the administrative act as an institute endowed with intense attributes, among others, the presumption of legality, mandatory and enforceability vis-à-vis its recipients. These characteristics recognized by the legislator are justified in the vicarial (helpful) function of the State Administration in the service of the general interest. However, in order to the administrative decision expressed in an administrative act benefits from those attributes, it must comply with essential formalities that the law imposes on it. In this paper one of these formalities is addressed, which is the notification in the event of acts of particular effects. Its connection with the principle of due process is highlighted, configuring a duty of the Administration with significant legal effects. On the other hand, the breach of the duty to notify has important effects both for the administrator and his assets, and for the realization of the purpose sought by the administrative decision. 
KEYWORDS Administrative procedure, notification of the administrative act, administrative act, due process.

\section{Introducción}

El procedimiento administrativo asociado a la producción del acto administrativo ha cobrado mayor significación en el escenario del nuevo constitucionalismo, que tiene como eje el respeto a la dignidad y las garantías que protegen al ciudadano. Esto constituye un cambio fundamental en la reflexión de las instituciones administrativas, que buscan no solo balancear debidamente el ejercicio del poder público sino, especialmente, evitar el abuso de poder y defender los espacios de libertad.

El propósito de este artículo consiste en destacar la importancia de un trámite esencial e imprescindible como colofón del procedimiento administrativo, cual es la notificación del acto administrativo terminal. Se trata de analizar de manera precisa las formalidades que debe cumplir este trámite, los efectos de la notificación y las consecuencias jurídicas de su omisión.

\section{El deber de notificar los actos administrativos y el debido proceso}

El deber de notificar los actos administrativos está estrechamente ligado al principio del debido proceso. Si bien la Constitución Política no se refiere en específico ni tampoco enuncia este principio, no hay discusión doctrinal en relación con la afirmación que el contenido del artículo 19 numeral $3 .^{\circ}$ inciso sexto ${ }^{1}$ expresa esta decisión del constituyente (Comisión Ortúzar, 1975: 516-517), ${ }^{2}$ al emplear dos adjetivos que conectan con el principio del debido proceso; esto es, el enunciado del inciso sexto del citado precepto utiliza dos adjetivos que invocan valores constitucionales complementarios: «racional», referido a las garantías procesales mínimas, y «justo», referido a una exigencia sustantiva que emana de los valores de la Constitución. Tanto en la redacción de la Comisión Ortúzar de la Constitución de 1980 (Comisión Ortúzar, 1975: 513)³ como en la

1. El citado precepto ordena: «Toda sentencia de un órgano que ejerza jurisdicción debe fundarse en un proceso previo legalmente tramitado. Corresponderá al legislador establecer siempre las garantías de un procedimiento y una investigación racionales y justos».

2. En la Comisión de Estudios de la Nueva Constitución se planteó la disyuntiva de enunciar el principio del debido proceso, pero al reconocer que este no tiene la misma interpretación en el derecho comparado (dado los procesos históricos singulares, especialmente, en el ámbito anglosajón) se optó por no emplear este concepto sino más bien establecer una serie de mandatos y reenvíos al legislador a fin de que sea este el que precise cuáles serán las garantías que se introducirán en el ordenamiento a fin de asegurar la efectividad del debido proceso en cualquier instancia de ejercicio del poder público (particularmente, en los ámbitos jurisdiccional y administrativo).

3. En palabras del comisionado Diez, las garantías procesales «se deben aplicar no solo al individuo frente al Poder Judicial, sino también al individuo frente a la administración, que en muchos casos está ejerciendo realmente muchas funciones de carácter judicial, de modo que no solo se debe limitarlas frente 
interpretación del Pacto de San José de Costa Rica que ha realizado a través de sus sentencias la Corte Interamericana de Derechos Humanos (Corte IDH), no hay duda de que las garantías del debido proceso son exigibles en sede judicial como administrativa.

En especial, para la Corte IDH es relevante que toda aquella autoridad pública que resuelva sobre derechos de las personas se sujete a las exigencias del debido proceso, lo que ha llevado a que el principio formulado originalmente en sede judicial la rebase y se le reconozca como necesario en todo procedimiento en que se puedan determinar derechos y obligaciones $y$, por tanto, afectar derechos fundamentales ( $\mathrm{CIDH}, 2007) .^{4}$

Así las cosas,

el principio del debido proceso sustenta un conjunto de garantías que son consecuencia del sistema democrático constitucional cuya afirmación ha permitido y fomentado su expansión así como su permanente evolución. ${ }^{5}$ En ese sentido, no se lo conceptualiza como una regla jurídica con un contenido fijo sino que tiene una fuerza para desarrollarse directamente proporcional a la consolidación de la Constitución como paradigma que conlleva la "juridificación de la democracia” (Camacho Cépeda, 2015: 1038-1039).

Ello justifica la amplia manifestación que este principio debe prodigar en la esfera administrativa, con el objeto de evitar prácticas arbitrarias en el ejercicio del poder público que vulneren los derechos fundamentales.

Examinar la obligación de notificación como expresión del principio del debido proceso nos conecta con la institución clave de la construcción del régimen administrativo, cual es el acto administrativo. Ciertamente, no hay discusión en torno a que el régimen administratif, sistema en el cual nos adscribimos, nace en torno a la institución

a lo que es realmente el Poder Judicial, sino que estas garantías procesales mínimas se deben hacer también aplicables al proceso o determinaciones de carácter administrativo que afecten la vida y la honra de las personas».

4. La Corte IDH, de acuerdo con lo destacado por la Comisión Interamericana de Derechos Humanos, «ha establecido la obligación de los Estados de contar con reglas claras para el comportamiento de sus agentes, a fin de evitar márgenes inadecuados de discrecionalidad en la esfera administrativa, que puedan fomentar prácticas arbitrarias o discriminatorias... La Corte IDH ha tenido oportunidad de remarcar la plena aplicabilidad de la garantía (del debido proceso legal) en sede administrativa».

5. El intérprete constitucional también ha reconocido la amplitud de la garantía del debido proceso como contenida en el artículo 19 numeral 3 de la Constitución, en la sentencia citada del 2 de enero de 2007, en la cual se señala: «Undécimo: Que la primera de las garantías constitucionales que los requirentes consideran infringidas es la del debido proceso, consagrada en el inciso quinto del numeral $3 .^{\circ}$ del artículo 19 constitucional. Dicha garantía, como se desprende de la simple lectura del precepto constitucional en cita, ha sido contemplada por el constituyente respecto de los órganos que ejercen jurisdicción, concepto que es más amplio que el de tribunales judiciales y comprende, por tanto, a órganos administrativos en la medida en que efectivamente actúen ejerciendo funciones jurisdiccionales. Por tanto, resulta determinante establecer si, en el caso bajo examen, el órgano administrativo que es la Dirección General de Aguas ha ejercido o no facultades de esa índole» (Sentencia del Tribunal Constitucional, rol 513-06, 2007, considerando undécimo). 
«acto administrativo» que constituía el núcleo central de la construcción del derecho administrativo. El fin de esta construcción permitía diferenciarlo del acto jurídico instituto del régimen privado. En palabras de (Cassagne, 2014: IX), «la teoría del acto administrativo fue, durante muchos años, el eje alrededor del cual giraba prácticamente todo el derecho administrativo».

El acto administrativo ha sido estudiado ampliamente en todas sus complejidades, pues sigue caracterizando sin duda la formalidad, por excelencia, en la que el poder administrativo se expresa y causa estado. La Ley 19.88 o define al acto administrativo como una «decisión escrita» adoptada por la Administración; asimismo, es una «decisión formal» en la cual se contienen declaraciones de voluntad realizadas en el «ejercicio de una potestad pública» y la forma regular que adopta es la de «decreto» o «resolución». Efectivamente, esta decisión administrativa está asociada a un procedimiento administrativo, que se constituye en el íter que ha de recorrerse para la producción de un acto administrativo terminal (Ley 19.880, artículo 18). ${ }^{6}$ De este modo, el procedimiento es el cauce que conduce a la Administración, particularmente, en sus relaciones con los administrados, a fin de que estos tengan garantizados sus medios de defensa frente a la arbitrariedad del ejercicio del poder. Así, el procedimiento administrativo como instituto que limita el poder y protege al ciudadano es expresión del derecho que busca el ejercicio racional de las potestades públicas y la realización de la justicia inspirada en las claves constitucionales de las que debe estar imbuido todo el ordenamiento jurídico.

La juridificación del ejercicio del poder a través del procedimiento administrativo que respeta el debido proceso hace realidad el control que el Derecho está llamado a ejercer como soporte eficaz y sólido de un Estado justo. En suma, el procedimiento administrativo se constituye en un importante instrumento de garantía de los derechos de los particulares, pues condensa muchas de las formalidades que la Administración debe cumplir para el ejercicio de los poderes que el ordenamiento le reconoce. Conforme expresa Barnés Vásquez, el procedimiento administrativo:

Constituye un mecanismo que coadyuva a la correcta aplicación del derecho (por ejemplo, para determinar si procede o no la autorización solicitada). Sirve con ello de garantía de acierto de la decisión y de defensa de los derechos (Barnés Vásquez, 2011: 1).

Una vez dictado el acto administrativo, para su ejecución y eficacia se requiere ponerlo en conocimiento del destinatario, es decir, de quienes se verán afectados ya sea positiva o negativamente. Según Moraga Klenner:

La comunicación del acto administrativo es la materialización del principio general de que los actos administrativos están sometidos a publicidad y transparencia (Ley 18.575 de 1986, artículos 13 y 14). La comunicación de un acto administrativo no es una condición para la debida regularidad jurídica del acto, sino que es una verdadera condición

6. El artículo 18 de la Ley 19.880 define al procedimiento como «una sucesión de actos trámite vinculados entre sí, emanados de la Administración y, en su caso, de particulares interesados, que tiene por finalidad producir un acto administrativo terminal». 
esencial de su existencia [...] La LBPA [Ley 19.880] ha cuidado de imponer a la Administración el deber de notificar el acto administrativo (Moraga Klenner, 2007: 296 y 299).

En general las notificaciones asociadas al procedimiento administrativo pueden ser de dos tipos:

- las notificaciones a realizarse en el curso de la tramitación del procedimiento; y,

- las notificaciones a efectuarse después de la finalización del procedimiento administrativo.

\section{Notificaciones durante la tramitación del procedimiento administrativo}

De acuerdo con la norma legal, el procedimiento administrativo está plagado de actos administrativos trámite (que son los que se dictan para impulsar el procedimiento), los que deben notificarse a los interesados. Para ello, cuando el procedimiento se ha iniciado a solicitud de parte, el legislador permite al interesado identificar el medio preferente o señalar el lugar en donde deberán realizarse las notificaciones (Ley 19.880, artículo 30 letra a). Sin embargo, la ley no despeja la duda si esta facultad también se le reconoce al interesado en un procedimiento administrativo iniciado de oficio.

La Ley 19.88 o tiene cuidado en consignar la obligación de la Administración de comunicar a los interesados, con la suficiente antelación, el inicio de las actuaciones necesarias para la realización de las pruebas que hayan sido admitidas en la instrucción del procedimiento (artículo 36). Más aún, el legislador precisa que en dicha comunicación la Administración deberá expresar el lugar, fecha y hora en que se practicará la prueba. De no cumplirse con lo que el legislador ha ordenado, id est, la Administración no ha realizado la notificación o ha omitido consignar en ella alguna de las precisiones preceptuadas, tanto la actuación omisiva como la notificación realizada deben entenderse como irregulares y antijurídicas, pues han menoscabado la posición del interesado en el procedimiento administrativo. En el marco de su tramitación, la notificación es una garantía para la efectividad del principio de contradictoriedad (Ley 19.880, artículo 10) que supone asegurar a los interesados el derecho a la defensa de sus derechos e intereses comprometidos en el procedimiento administrativo, mediante la presentación, en cualquier momento, de alegaciones y la aportación de documentos que, a su juicio, deben ser considerados por la autoridad antes de dictar su decisión final.

Lo anteriormente señalado permite sustentar que el acto trámite de actuación de pruebas puede ser impugnado al configurarse una de las excepciones contenidas en el artículo 15 inciso segundo de la Ley 19.880,7 que habilitan a impugnar un acto trámite

\footnotetext{
7. El citado artículo no permite la impugnación de los actos trámite salvo por excepción. Su texto principalmente se dirige a los actos terminales, como establece su enunciado: "Artículo 15. Principio de impugnabilidad. Todo acto administrativo es impugnable por el interesado mediante los recursos administrativos de reposición y jerárquico. [...] Sin embargo, los actos de mero trámite son impugnables solo cuando determinen la imposibilidad de continuar un procedimiento o produzcan indefensión».
} 
en el que se haya producido indefensión. Como puede advertirse, si la Administración no cumple con notificar las actuaciones de prueba o si esta notificación no se ejecuta satisfaciendo las exigencias legales ordenadas, se afecta la posición del interesado, pues lo coloca en una situación de indefensión.

\section{Notificaciones luego de finalizado el procedimiento administrativo}

Como es sabido, el procedimiento administrativo en su totalidad está encaminado a la producción de la decisión final que, de acuerdo con la ley, tiene las características de

presunción de legalidad, de imperio y exigibilidad frente a sus destinatarios, desde su entrada en vigencia, autorizando su ejecución de oficio por la autoridad administrativa, salvo que mediare una orden de suspensión dispuesta por la autoridad administrativa dentro del procedimiento impugnatorio o por el juez, conociendo por la vía jurisdiccional (Ley 19.880, artículo 3 , inciso final).

Todas estas prerrogativas de las que goza la decisión administrativa están impregnadas del poder público que la origina. De ahí la importancia que tiene el aseguramiento de las garantías del debido proceso en el procedimiento administrativo, que desembocará en una decisión caracterizada por el privilegio de la autotutela declarativa y ejecutiva.

La Ley 19.880 regula en su capítulo II todo lo relacionado con el procedimiento administrativo (normas básicas, sus etapas: iniciación, instrucción y finalización). El cuarto párrafo de este título, denominado "Finalización del procedimiento», entre otros, establece el contenido indispensable de la resolución final (artículo 41). Seguidamente, se aborda en el capítulo III la publicidad y ejecutividad de los actos administrativos, el que contiene normas sobre la notificación y publicación. Para el presente estudio referiremos el instituto de la notificación especialmente a los actos terminales, vale decir, al acto que contiene la decisión final del procedimiento administrativo.

La notificación de la decisión final es inexcusable en acatamiento del principio de inexcusabilidad (Ley 19.880, artículo 14, inciso primero) ${ }_{,}^{8}$ cualquiera haya sido la forma de iniciación del procedimiento. Este deber de notificar evita que se produzca indefensión y eso es concordante con el acatamiento del principio del debido proceso. Además, el principio de inexcusabilidad no solo garantiza que la Administración resolverá de forma expresa el procedimiento - evitando así incurrir en el repudiable silencio administrativo-, sino que también asegura que esta resolución se comunicará al interesado. Ciertamente, el legislador debió haber empleado la palabra «publicidad» (que engloba tanto a los actos administrativos de efectos generales como a los de efectos particulares), en lugar de emplear la expresión «notificación», porque la obligación

8. El citado artículo enuncia el principio del siguiente modo: «Artículo 14. Principio de inexcusabilidad. La Administración estará obligada a dictar resolución expresa en todos los procedimientos y a notificarla, cualquiera que sea su forma de iniciación». 
de este trámite solo se refiere a los actos de efectos particulares y el principio de inexcusabilidad se aplica a todos los procedimientos y actos administrativos.

Para la determinación de la opción adecuada de publicidad que se debe cumplir respecto de un acto administrativo, el legislador emplea el criterio de los efectos que este produce. De este modo, el legislador distingue entre «actos de efectos individuales» (Ley 19.880, artículos 45-47) y «actos de general aplicación» a los que además se suman otros actos que la ley indica (artículos 48-49).

La notificación es la forma correcta y ordinaria de publicidad para los actos administrativos de efectos individuales, salvo que se desconozca el paradero de las personas afectadas, en cuyo caso deberá publicarse en el Diario Oficial. La norma legal ordena que la notificación a los interesados debe realizarse:

- conteniendo «su texto íntegro» (Ley 19.88o, artículo 45 inciso primero) (Moraga Klenner, 2007: 297); ${ }^{9}$

- en un brevísimo plazo: «a más tardar en los 5 días siguientes a aquel en que ha quedado totalmente tramitado el acto administrativo» (Ley 19.880, artículo 45 inciso segundo); $y$

- empleando la formalidad escrita, bien sea por carta certificada o practicarse de modo personal (Ley 19.880, artículo 46).

De acuerdo con las previsiones tomadas por el legislador, es correcto señalar que la notificación es la garantía que, acorde con el principio del debido proceso, tiene el interesado de que conocerá a cabalidad la decisión de la autoridad administrativa, y no se le coloca en una situación de indefensión. La notificación de los actos administrativos de efectos particulares no es una concesión al interesado, sino es expresión del debido respeto a sus derechos e intereses que le corresponde. Solo así puede surgir la certeza y seguridad jurídicas que demanda el correcto ejercicio del poder administrativo.

La notificación de los actos administrativos, en los casos que la ley así lo ordena, tiene también importantes consecuencias jurídicas. En razón de ello, el legislador básico, fundado en el principio de no formalización, construye una presunción a este respecto denominada «notificación tácita» (Ley 19.880, artículo 47), pues ello es esencial para la eficacia del procedimiento administrativo y su definición final. Los efectos jurídicos que desencadena la notificación solo son posibles una vez que esta se ha realizado. En caso de que la notificación no haya sido efectuada o habiéndolo sido adolezca de vicio, de acuerdo con el citado precepto se entenderá que la notificación ha sido debidamente practicada, solo si a quien afecte realiza cualquier gestión en el procedimiento con posterioridad al acto que suponga «necesariamente su conocimiento». Pero, asimismo, no

9. De acuerdo con el autor citado: «La circunstancia de que la norma disponga que la notificación del acto administrativo debe contener su texto íntegro, hace suponer que el destinatario del mismo pueda conocerlo en su integridad, no solamente en la parte decisoria o resolutiva del mismo, incluyendo, por cierto, la motivación pertinente y todas las demás consideraciones tenidas en cuenta por el órgano administrativo». 
se configura el indicio que la ley exige para reconocer la notificación tácita si el afectado ha reclamado previamente de la falta de notificación o de la nulidad de esta. En consecuencia, se debe entender que la presunción de «notificación tácita» está admitida no solo para impulsar o destrabar el procedimiento administrativo, a fin de que llegue a su término, entendiéndose que, una vez iniciado, su finalización no responde solo al interés general, sino que, fundamentalmente, para no perjudicar al interesado.

\section{Los efectos de la notificación (y de la omisión del deber de notificar)}

En relación con las consecuencias de la notificación podemos distinguir los siguientes efectos más importantes.

\section{Certeza para el cómputo de los plazos}

El procedimiento administrativo está plagado de plazos relacionados con su tramitación (resolución de iniciación, actos de instrucción, etcétera). La notificación de estos actos trámite es la garantía del respeto del principio de contradictoriedad, manifestación del derecho a «ser oído» en plano de igualdad a fin de participar en el debate de los hechos y su calificación jurídica. Asimismo, luego de finalizado el procedimiento, los plazos importantes son aquellos señalados para ejercer las vías recursivas o aquellos que la autoridad otorga para la ejecución de sus decisiones y es en relación con todos estos plazos que la notificación, cuando es ordenada por la ley, incide para dar certeza sobre la oportunidad en que deben practicarse.

Las disposiciones básicas del procedimiento contenidas en la Ley 19.880 determinan la forma como se computan los plazos. De acuerdo con el Diccionario del Español Jurídico de la Real Academia Española, ${ }^{10}$ computar significa contar algo en número por lo que estas reglas nos indican a partir de cuándo corren los plazos fijados en la ley. La Ley 19.880, además de establecer la regla general que todo plazo debe entenderse de días hábiles administrativos (excluyendo los días sábados, domingos y festivos), señala que los plazos «se computarán desde el día siguiente en que se notifique o publique el acto...» (artículo 25). ${ }^{11}$ Con interpretación a contrario, se deduce que ningún plazo puede empezar a correr si la notificación, cuando es ordenada por la ley, no se ha practicado. Esta conclusión también es arribada por la doctrina. En tal sentido, el maestro Jesús González Pérez, al comentar la Ley 19.88o señaló que «la notificación, aparte de ser el medio de llegar a conocer su contenido, opera como garantía que le permite reaccionar por las vías admisibles para hacer valer los posibles vicios de que adolezca el acto de notificación»

10. Real Academia Española, Diccionario del Español Jurídico, disponible en https://dej.rae.es/.

11. La citada disposición establece: «Artículo 25. Cómputo de los plazos del procedimiento administrativo. Los plazos de días establecidos en esta ley son de días hábiles, entendiéndose que son inhábiles los días sábados, los domingos y los festivos. [...] Los plazos se computarán desde el día siguiente a aquél en que se notifique o publique el acto de que se trate o se produzca su estimación o su desestimación en virtud del silencio administrativo». Los destacados son nuestros. 
(González Pérez, 2003: 382). Por su parte, Jara Schnettler hace hincapié que «legalmente los actos de la Administración destinados a producir efectos externos de naturaleza individual, $[\ldots]$ solo entran en vigencia y tienen efectos vinculantes para sus destinatarios desde que son notificados, [pues] debe cumplirse esta formalidad esencial» (Jara Schnettler, 2012: 147). Todo ello es reforzado por el contenido de la norma contenida en el artículo 23 de la Ley 19.880, que dispone: «Los términos y plazos establecidos en esta y otras leyes obligan a las autoridades y personal al servicio de la Administración en la tramitación de los asuntos, así como a los interesados en los mismos».

\section{Marca el inicio de la vigencia del acto administrativo}

La notificación señala desde cuándo la decisión orgánica potestativa «existe» en la vida jurídica y tiene la aptitud para obligar a partir de la conjunción de los hechos y el derecho sobre los que se funda y el cumplimiento de los trámites que son exigidos para su entrada en vigor, todo lo cual permite al acto administrativo ubicarse en la realidad jurídica conforme a los principios de jerarquía, temporalidad y especialidad. Atendiendo a la capacidad innovadora que tienen los actos administrativos para generar derechos e imponer obligaciones, es a partir de su entrada en vigencia que estos tienen la aptitud para ser aplicables y para ser exigidos imperativamente. Ello por cuanto desde su entrada en vigencia los actos administrativos gozan de presunción de legalidad, imperio y exigibilidad frente a sus destinatarios (Ley 19.880, artículo 3).

La relevancia del momento de inicio de la vigencia del acto administrativo está estrechamente relacionada con la opción por las decisiones formales escritas expresadas en decretos o resoluciones que son las que el legislador reconoce como actos administrativos, constituyéndose para la Administración en la fórmula necesaria a la que debe recurrir para adoptar y expresar su voluntad. En este sentido se expresa la jurisprudencia administrativa:

[En el] artículo 3 se consagra expresamente el principio de que los actos que emanen de tales entes deben materializarse a través de actuaciones escritas y formales, en las que se contenga su declaración de voluntad sobre la materia de que se trate (Dictamen de la Contraloría General de la República 49.313, de 2006). ${ }^{12}$

\footnotetext{
12. En el mismo sentido, el Dictamen de la Contraloría General de la República 39.979 de 2010 interpreta la norma del artículo 3 de la Ley 19.880 subrayando el carácter formal del acto administrativo: «corresponde aclarar que tales pronunciamientos recayeron en sendas presentaciones referidas a la potestad de ciertos órganos públicos para impartir instrucciones, las cuales, en la medida que no constituyan una decisión formal de la Administración, ni importen una declaración de juicio, constancia o conocimiento de alguno de sus órganos, efectivamente, no se enmarcan en ninguno de los conceptos de acto administrativo que describe el artículo 3 de la Ley 19.880».
} 


\section{Certeza del inicio de la eficacia ad extra ${ }^{13}$}

La notificación es la que allana la producción de efectos externos, esto es, permite que se despliegue toda la capacidad del acto administrativo para producir efectos jurídicos, lo que es su característica principal. De este modo, para que el acto administrativo cumpla el objetivo para el cual ha sido dictado, no basta que el acto se presuma legal y que esté vigente; es necesario, además, que cumpla con los requisitos formales para ser eficaz; que son, para el estudio que aquí interesa, ${ }^{14}$ la notificación o la publicación según lo que mandata la Ley 19.880 en su capítulo III. El legislador precisa estas exigencias en el artículo 51 inciso segundo de la Ley 19.880, determinando, respecto de los efectos jurídicos de los actos administrativos expresados en decretos o resoluciones, que aquellos se producirán desde su notificación o publicación «según sean de contenido individual o general».

Desde la manifestación positiva de voluntad de la Administración, el acto administrativo está orientado a producir efectos jurídicos. Luego, el acto administrativo es eficaz cuando surte efectos jurídicos sobre sus destinatarios a los cuales debe aplicarse, pero para que se aplique a sus destinatarios el legislador ha impuesto la necesaria publicidad del acto, lo que se cumple a través de la publicación o de su notificación (Ley 19.88o, capítulo III, párrafos I y II). Este mandato del legislador tiene una finalidad garantizadora de los derechos de los ciudadanos en su relación con la Administración, complejo orgánico poseedor de potestades exorbitantes. Con ello, se busca que el ciudadano no esté en situación de indefensión frente a un acto potestativo, por lo que la ley garantiza a los destinatarios del acto que este no producirá efectos jurídicos sino desde su publicación o notificación, según sean de contenido individual o general (Ley 19.880, artículo 51, inciso segundo). La Contraloría General de la República destaca esta finalidad garantizadora:

La notificación tiene por objeto hacer saber al afectado la voluntad de la Administración expuesta en el instrumento que se comunica, diligencia que se cumple cuando el servidor toma conocimiento cierto del contenido del documento por cualquier medio auténtico y fidedigno, lo que se logra plenamente con la entrega de una copia simple del respectivo instrumento. (Dictamen de la Contraloría General de la República 61.387, de 2012)

A este respecto, es fundamental determinar desde qué momento (dies a quo) el acto administrativo de efectos particulares es eficaz y, en consecuencia, puede producir

13. El acto administrativo desde que la autoridad lo suscribe tiene una eficacia ad extra indudable. Esta eficacia al interior de la organización administrativa está orientada a cumplir los requisitos para que la decisión orgánica pueda ser eficaz ad extra y ello está relacionado con el cumplimiento de algunos trámites como toma de razón, publicación, etc. que incluso suelen estar contenidos en las estipulaciones de cierre de las resoluciones, tales como «anótese, tómese razón y publíquese».

14. El inicio de la eficacia puede también estar sometido a otras exigencias como el registro, la toma de razón, la toma de posesión del cargo, etcétera. 
los efectos jurídicos sancionados por la autoridad administrativa. En tal sentido, Jara Schnettler hace hincapié que «legalmente los actos de la Administración destinados a producir efectos externos de naturaleza individual [...] solo entran en vigencia y tienen efectos vinculantes para sus destinatarios desde que son notificados, [pues] debe cumplirse esta formalidad esencial» (Jara Schnettler, 2012: 147). En el mismo sentido, la jurisprudencia contralora ha afirmado:

Las resoluciones... solo regirán desde la fecha de su notificación a los interesados conforme al principio de que los actos administrativos producen efectos legales desde la fecha de su publicación o notificación según proceda. (Dictamen de la Contraloría General de la República 28.814, de 1976)

$\mathrm{Y}$ «el acto administrativo [...] no produjo sus efectos, ya que la notificación de esos actos es una condición esencial para su validez, sin la cual carecen de toda eficacia» (Dictamen de la Contraloría General de la República 18.661, de 1994). Por consiguiente, la comunicación del acto como condición de su eficacia es una formalidad esencial y crucial de la que ya no cabe dudar, atendiendo los preceptos de la Ley 19.880 y la jurisprudencia administrativa y judicial, que ratifican el criterio que los actos administrativos solo entran en vigor y son eficaces una vez notificados a los interesados.

Pero ¿qué pasa si la Administración no realiza la notificación? La respuesta a esta interrogante es de vital importancia para determinar la eficacia del acto administrativo, especialmente, en su faz ejecutiva, y conecta con los principios generales del derecho, como son la buena fe, la seguridad y certeza jurídica. La comunicación del acto, como condición de su eficacia, es una formalidad básica. La obligación de notificar la resolución administrativa es el modo de publicitar los actos administrativos de efectos individuales. Su finalidad primordial es lograr que el acto administrativo sea conocido por el interesado (el artículo 45 de la Ley 19.880 exige que ésta debe contener el texto íntegro de la resolución), para que pueda conocer la decisión administrativa, bien sea para aceptarla o para reaccionar contra la misma con todas las garantías. Por ello, la Administración tiene la responsabilidad de realizar las notificaciones con una especial dosis de escrupulosidad, celo y respeto de las normas que regulan los actos de comunicación; y tiene también la carga de acreditar la realidad y regularidad de las notificaciones. La eficacia del acto administrativo dependerá del que se comunique al interesado con arreglo a derecho. En este aspecto, habrá de atenderse no solo a la regulación expresa de la institución, sino muy especialmente a la jurisprudencia que establece los requisitos y garantías que han de cumplirse en la práctica de las notificaciones administrativas. Si bien uno de los principios del procedimiento administrativo es su no formalización, ello tiene como límite las garantías que se deben respetar a los interesados a fin de no vulnerar su derecho a la defensa y a un procedimiento racional y justo, respetando a cabalidad el debido proceso.

De acuerdo con el artículo 51 de la Ley 19.880, cuando se trata de actos administrativos de efectos particulares, las resoluciones solo "producirán efectos jurídicos desde su notificación». En concordancia con ello, el artículo 50 prohíbe a la Administración 
la realización de «[toda] actuación material de ejecución de resoluciones que limite derechos de los particulares sin que previamente haya sido adoptada la resolución que le sirva de fundamento jurídico». En tal virtud, el legislador ordena que antes de realizar una «ejecución material de resoluciones [la autoridad] estará obligado a notificar al particular interesado la resolución que autorice la actuación administrativa». Siguiendo este orden de prescripciones, para este análisis interesa destacar una consecuencia esencial del acto administrativo, cuál es su calidad de erigirse en título jurídico indispensable para su ejecución. A ello se suman las características mencionadas en los párrafos precedentes, como la de gozar de presunción de validez; su cualidad de imperatividad (por ser expresión de una potestad que encierra el ejercicio de soberanía por la Administración); su ejecutoriedad, en virtud de la cual se debe cumplir la decisión expresada en el acto correspondiente; y su propiedad de estabilidad, lo que alude a la persistencia de los efectos del acto mientras no se haya producido la invalidación, revisión o haya ocurrido su decaimiento.

De no contar con un acto administrativo que haya cumplido con las exigencias para su plena eficacia - entre ellas, la notificación en los casos que es preceptiva- se estaría configurando una situación antijurídica que se reconoce como «vía de hecho» porque la Administración carecería de título jurídico para la ejecución de la decisión administrativa. Como señala el connotado administrativista Juan Carlos Cassagne:

El concepto de vía de hecho administrativa, obra de la jurisprudencia francesa, pertenece al campo de la ilegitimidad y comprende todos aquellos comportamientos materiales que, sin alcanzar a configurar una declaración, implican una grosera o grave vulneración del ordenamiento jurídico (Cassagne, 2014: 134).

La «vía de hecho» es una situación que genera violencia contra el administrado y sus bienes, pues se le coloca en una posición de indefensión que rechaza el ordenamiento jurídico. La omisión de la preceptiva notificación convierte toda actuación material orientada a la ejecución de la decisión administrativa en vías de hecho que vulneran las garantías constitucionales del debido proceso que debe ser respetado por el poder público, máxime en un Estado de Derecho que debe ser servicial y garante de los derechos fundamentales. Jesús González Pérez, respecto de las disposiciones normativas contenidas en la Ley 19.880 referidas a la ejecución de los actos administrativos, elogia la protección que dispensan:

consagrando [entre las] normas generales una, de elemental garantía, que conlleva la interdicción de la vía de hecho, al prohibir la iniciación de cualquier actuación material que limite derechos subjetivos sin que previamente se haya notificado la resolución que le sirva de fundamento jurídico [artículo 50] (González Pérez, 2003: 383).

En el mismo sentido, Cano señala:

Un acto administrativo es eficaz cuando produce los efectos que le son propios, lo cual depende de su contenido. Esta eficacia, que suele llamarse externa, inmediata o 
formal del acto, equivale a su aparición efectiva en la realidad jurídica, que solo tiene lugar con la notificación al destinatario del mismo. Desde ese momento el acto es impugnable por este... (Cano Campos, 2004: 171-172).

Por su parte, Caballero acentúa la interpretación garantista que debe darse al trámite de notificación en relación con la eficacia externa de la decisión administrativa. A este respecto, señala:

No tiene trascendencia el día en que la autoridad competente firma la resolución de un expediente, sino el día en que efectivamente recibe en su domicilio la comunicación en regla de ese escrito. Ese día es el relevante, tanto a efectos de recurso, como de control objetivo de si se ha superado el máximo de tramitación a efectos del posible silencio o perención del procedimiento según proceda (Caballero Fernández, 1999: 232-233).

Concordando con los criterios señalados se ha pronunciado la jurisprudencia administrativa interpretando en el mismo sentido las disposiciones de la Ley 19.880:

Por regla general, los actos administrativos nacen a la vida jurídica desde el momento de su dictación, empezando a producir sus efectos desde el instante que se notifica a los interesados su existencia. (Dictamen de la Contraloría General de la República 3.769, de 2000)

$\mathrm{Y}:$

La notificación de un acto administrativo es, dentro del proceso respectivo, un requisito de eficacia jurídica, por lo que mientras no ha sido válidamente comunicado, no produce efecto alguno y es inoponible al afectado. (Dictamen de la Contraloría General de la República 8.148, de 1993)

\section{Conclusiones}

Podemos decir que la trascendencia del instituto de la notificación de los actos administrativos se sustenta en las siguientes conclusiones:

- El deber de notificar los actos administrativos está estrechamente ligado al principio del debido proceso y particularmente conectado con la institución clave del régimen administrativo: el acto administrativo, el cual está dotado de prerrogativas intensas que expresan su origen potestativo y soberano, razón por la cual goza de presunción de legalidad, imperio y exigibilidad.

- Esta decisión administrativa debe producirse como resultado de un procedimiento administrativo. El procedimiento administrativo como instituto que limita el poder y protege al ciudadano es un importante instrumento de garantía de los derechos de los particulares, pues condensa muchas de las formalidades que la Administración debe cumplir para el ejercicio de los poderes que el ordenamiento le reconoce. 
- La publicidad de las decisiones administrativas contenidas en un acto administrativo es inexcusable y se realiza según lo determina el legislador mediante la publicación o bien la notificación.

- La notificación es la forma correcta y ordinaria de publicidad para los actos administrativos de efectos individuales.

- La omisión del deber de notificar los actos trámite o realizar está notificación sin guardar los requisitos que impone la ley (expresando lugar, fecha y hora) habilitan por excepción a recurrir el acto trámite, ya que estos por norma general no son recurribles. De igual modo, durante la tramitación del procedimiento administrativo la notificación es una garantía para la efectividad del principio de contradictoriedad que se orienta a asegurar a los interesados la defensa de sus derechos e intereses comprometidos.

- La notificación de la decisión final es inexcusable en acatamiento del principio de inexcusabilidad, orientado a obtener una decisión final de la autoridad y a evitar que se produzca una situación de indefensión.

- Una vez culminado el procedimiento administrativo, la notificación del acto terminal es indispensable y debe realizarse cumpliendo con las exigencias de los artículos 45 y 46 de la Ley 19.880, estipuladas a favor del respeto al debido proceso, y de generar certeza y seguridad jurídicas e impedir situaciones de indefensión de los interesados.

- La notificación del acto administrativo genera importantes efectos jurídicos que no pueden producirse en el caso de que esta no se haya realizado correctamente o se haya omitido su realización.

- La notificación del acto administrativo genera certeza para el cómputo de plazos, marca el inicio de la vigencia del acto administrativo y da certeza del inicio de la eficacia externa del acto administrativo. La omisión del deber de notificar puede colocar al destinatario en una posición de indefensión y en riesgo de soportar actuaciones antijurídicas que se califican como «vías de hecho» porque la Administración carece de título para ejecutar la decisión formal que ha adoptado.

\section{Referencias}

BARNÉS VÁsQUEZ, Javier (2011). «Hacia procedimientos administrativos de tercera generación». Revista de Derecho Administrativo, 5: 1-24.

Caballero Fernández, Rafael (1999). Prescripción y caducidad en el ordenamiento administrativo. Madrid: McGraw-Hill.

CAMACho CÉPedA, Gladys (2015). «La incidencia del ordenamiento internacional en la aplicación del debido proceso ante el Consejo para la Transparencia». En Manuel Núñez (editor), La internacionalización del derecho público. Actas de las XLII Jornadas Chilenas de Derecho Público. Valparaíso: Thomson Reuters, La Ley, PUCV. 
Cano Campos, Tomás (2004). La invalidez sobrevenida de los actos administrativos. Madrid: Thomson Civitas.

Cassagne, Juan Carlos (2014). El acto administrativo. México: Porrúa.

CIDH, Comisión Interamericana de Derechos Humanos (2007). El acceso a la justicia como garantía de los derechos económicos, sociales y culturales. Estudio de los estándares fijados por el Sistema Interamericano de Derechos Humanos. Parte III. Debido proceso administrativo y garantía de derechos sociales. Washington: Organización de los Estados Americanos. Disponible en http://www.cidh.org/countryrep/accesodesco7sp/Accesodesciii.sp.htm.

Comisión Ortúzar (1975). Actas de la Comisión de Estudios de la Nueva Constitución. Tomo III. Santiago de Chile: Biblioteca del Congreso Nacional. Disponible en https://www.bcn.cl/lc/cpolitica/actas_oficiales-r.

GonzÁlez PÉrez, Jesús (2003). «La ley chilena de procedimiento administrativo». Revista de Administración Pública, 162: 359-389. Disponible en https://dialnet.unirioja. es/descarga/articulo/784952.pdf.

Jara Schnettler, Jaime (2012). "Caducidad y notificación del reparo en el juicio de cuentas». Revista de Derecho Público, 77: 135-162. Disponible en https://revistas. uchile.cl/index.php/RDPU/article/view/30921.

Moraga Klenner, Claudio (2007). «La actividad formal de la Administración del Estado». En Rolando Pantoja Bauzá (director), Derecho administrativo chileno. Libro II, 2. ${ }^{\text {a }}$ parte. México: Porrúa.

\section{Sobre la autora}

Gladys Camacho Cépeda es abogada. Licenciada en Ciencias Jurídicas y Sociales de la Pontificia Universidad Católica del Perú, máster en Administración Pública de la Universidad de Alcalá y el Instituto Nacional de Administración Pública de España, y doctora en Derecho de la Universidad Carlos III de Madrid. Es profesora de Derecho Administrativo de la Facultad de Derecho y del Instituto de Asuntos Públicos de la Universidad de Chile. Su correo electrónico es gcamacho@derecho.uchile.cl. (iD https://orcid.org/o000-0003-4196-2372. 
